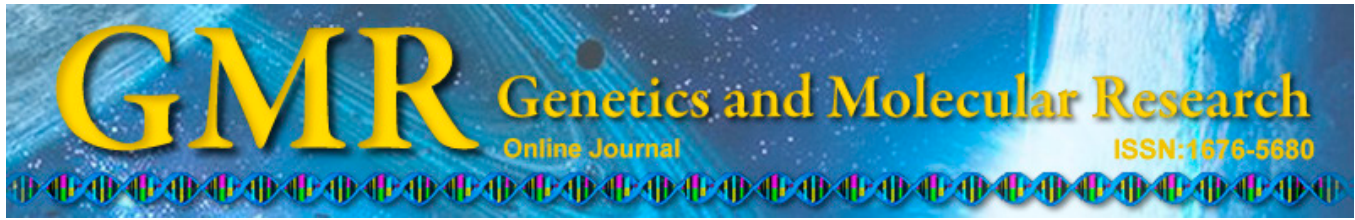

\title{
New microsatellite markers for the neotropical malaria vector Anopheles nuneztovari sensu lato
}

\author{
A.S. Cunha-Machado ${ }^{1}$ and V.M. Scarpassa ${ }^{2}$ \\ ${ }^{1}$ Laboratório Temático de Biologia Molecular, Coordenação de Biodiversidade, \\ Instituto Nacional de Pesquisas da Amazônia, Manaus, AM, Brasil \\ ${ }^{2}$ Laboratório de Genética de Populações e Evolução de Mosquitos Vetores de \\ Malária e Dengue, Coordenação de Biodiversidade, \\ Instituto Nacional de Pesquisas da Amazônia, Manaus, AM, Brasil \\ Corresponding author: V.M. Scarpassa \\ E-mail: vera@inpa.gov.br
}

Genet. Mol. Res. 13 (4): 8856-8861 (2014)

Received May 6, 2014

Accepted September 22, 2014

Published October 27, 2014

DOI http://dx.doi.org/10.4238/2014.October.27.26

\begin{abstract}
Anopheles nuneztovari sensu lato consists of cryptic species and genetic lineages, one of which is an important human malaria vector in the northern part of South America. Population structure and evolutionary genetics studies may help in the definition and delimitation of the species and lineages within this species complex, which is relevant information for organizations involved in malaria control efforts. In this study, 10 new microsatellite markers were isolated from 2 repeat-enriched genomic libraries of A. nuneztovari s.l. and were characterized in 37-48 mosquitoes of this species. All loci were highly polymorphic and encompassed 5-25 alleles per locus. The observed $\left(H_{\mathrm{O}}\right)$ and expected $\left(H_{\mathrm{F}}\right)$ heterozygosities ranged from 0.354 to 0.866 and from 0.613 to 0.932 , respectively. Six of the 10 new loci showed significant deviations from the HardyWeinberg equilibrium, and no linkage disequilibrium was detected. The loci described in this study were more polymorphic than the 18 previously characterized loci and appear to be promising markers for use in investigating the fine-scale population genetic structure
\end{abstract}


and the boundaries of the cryptic species and lineages within the $A$. nuneztovari complex.

Key words: Malaria vector; Microsatellite markers; Genetic diversity; Population genetics; Speciation

\section{INTRODUCTION}

Anopheles nuneztovari sensu lato (order Diptera, family Culicidae) has a large geographic distribution in northern South America. Currently, A. nuneztovari s.l. comprises a species complex with 3 cryptic species: Anopheles nuneztovari sensu stricto, Anopheles goeldii, and Anopheles dunhami (Scarpassa et al., 1996, 1999; Foster et al., 2013). A. nuneztovari sensu stricto, which is geographically distributed in Colombia and Venezuela, is predominantly anthropophagic and has proven to be an efficient human malaria vector (Gabaldón, 1981). A. goeldii, which is geographically distributed in the Amazon Basin comprising the Brazilian Amazon and Suriname, has been found to be infected with 3 Plasmodium species in 5 states of the Brazilian Amazon region (de Arruda et al., 1986; Tadei et al., 1998; Póvoa et al., 2001; Galardo et al., 2007). Although the status of $A$. goeldii as a malaria vector has not yet been clarified in the Brazilian Amazon region because it is predominantly zoophagic, it is likely to be a local malaria vector or a secondary vector (which can contribute to malaria transmission, but cannot sustain it without the presence of a primary vector). A. dunhami is morphologically and genetically closely related to A. nuneztovari s.s. and A. goeldii (Lounibos et al., 1998; Trindade and Scarpassa, 2002) and has a large area of overlap with $A$. goeldii (Scarpassa and Conn, 2011). However, A. dunhami has not been found to be infected with the malaria parasite. Along with the presence of three cryptic species in this complex, previous studies have also shown the existence of genetic lineages within A. nuneztovari s.l. in the Brazilian Amazon region (Mirabello and Conn, 2008; Scarpassa and Conn, 2011), suggesting an intriguing evolutionary history for this species complex. Thus, studies based on highly polymorphic markers with a faster evolutionary rate, such as microsatellites, may provide a better understanding of the genetic structure of $A$. nuneztovari s.l. Furthermore, the definition and delimitation of these cryptic species and lineages could illuminate the manner in which A. nuneztovari s.l. contributes to the distinct patterns of malaria transmission that are found in South America. A previous study (Cardoza et al., 2011) isolated and characterized 18 microsatellite loci in $A$. nuneztovari s.l., which have served as powerful markers that have allowed the investigation of the fine-scale population structure and evolutionary genetics of this species complex.

In the present study, we isolated 10 new microsatellite markers from 2 repeat-enriched genomic libraries of A. nuneztovari s.l. from Manaus (State of Amazonas, Brazil) and Nova Mazagão (State of Amapá, Brazil) and characterized these loci in 37-48 specimens from Manaus, Brazil.

\section{MATERIAL AND METHODS}

Two microsatellite-enriched libraries were constructed from 2 pools of $A$. nuneztovari s.l. (each containing 8 specimens) that were collected in either Manaus $\left(03^{\circ} 06^{\prime} \mathrm{S}, 60^{\circ} 01^{\prime} \mathrm{W}\right.$; State of Amazonas, Brazil) and Nova Mazagão $\left(00^{\circ} 07^{\prime} \mathrm{S}, 51^{\circ} 17^{\prime} \mathrm{W}\right.$; State of Amapá, Brazil). Genomic DNA was extracted from fourth instar larvae of $A$. nuneztovari s.l. using the phenol- 
chloroform method (Sambrook and Russell, 2001). The genomic DNA samples (5 $\mu \mathrm{g})$ extracted from each pool were digested separately with $R s a \mathrm{I}$, and the resulting DNA fragments were linked to Rsa21 and Rsa25 adapters. Pre-amplified ligated DNA was obtained by PCR using Rsa21 primers and purified with the QIAquick PCR Purification Kit (Qiagen, Germantown, MD, USA). DNA fragments containing putative markers were selected by hybridization with $(\mathrm{CT})_{8}$ and $(\mathrm{GT})_{8}$ repeats and biotin-linked probes and recovered with streptavidin-linked particles (Streptavidin MagneSphere Paramagnetic Particles; Promega, Madison, WI, USA). Selected fragments were linked to the pGEM-T easy vector (Promega), which was used to transform Escherichia coli XL1-blue competent cells, which were plated on X-Gal/IPTG Luria-Bertani (LB) agar and ampicillin $(100 \mathrm{mg} / \mathrm{mL})$ and allowed to grow overnight at $37^{\circ} \mathrm{C}$. Single white colonies were transferred onto microplates with $\mathrm{HM} / \mathrm{FM}$ medium containing ampicillin $(100 \mathrm{mg} / \mathrm{mL})$ and allowed to grow overnight. After the overnight growth period, 192 clones were selected and bi-directionally sequenced on an automated ABI PRISM 3130 Genetic Analyzer (Applied Biosystems, Thermo Fisher Scientific, Waltham, MA, USA) using T7 and SP6 primers, and the resulting sequences were assembled and edited using the SeqMan software (DNAStar Inc., Madison, WI, USA). Restriction sites were removed using the Microsat software (Risterucci et al., 2005) and microsatellite motifs were identified using the Simple Sequence Repeat Identification Tool (SSRIT), which is available online (Temnykh et al., 2001). Fifty-eight primer pairs were designed using the Primer Select software (DNAStar Inc.). For this purpose, we considered dinucleotides and trinucleotides with 5 or more repeats, as well as tetranucleotides and 4 or more repeats, and pentanucleotides with 3 or more repeats.

Of the 58 primer pairs designed, 28 successfully amplified their respective products. Of these successful primers, 18 loci were previously validated and characterized by Cardoza et al. (2011). The other 10 primer pairs were validated and characterized in the present study; 9 of these loci (Anu19 to Anu27) were from the Manaus library and 1 (Anu28) was from the Nova Mazagão library (Table 1). The level of polymorphism was estimated using 37-48 specimens of A. nuneztovari s.l. sampled from Manaus, Brazil. The microsatellite fragments were amplified by polymerase chain reaction (PCR) in a final volume of $10 \mu \mathrm{L}$ reaction solution containing 10-20 ng $(1.0 \mu \mathrm{L})$ DNA template, $1.0 \mu \mathrm{L}$ 10X buffer, $2.1 \mu \mathrm{L} 1 \mathrm{mM}$ dNTPs, 0.3 $\mu \mathrm{L} 50 \mathrm{mM} \mathrm{MgCl}_{2}, 0.4 \mu \mathrm{L} 4 \mathrm{mM}$ M13-tailed forward primer (Schuelke, 2000), $0.4 \mu \mathrm{L} 4 \mathrm{mM}$ M13-labeled primer (FAM, HEX, and TAMRA), $0.8 \mu \mathrm{L} 4 \mathrm{mM}$ reverse primer, $0.2 \mu \mathrm{L} 5 \mathrm{U} /$ $\mu \mathrm{L}$ Platinum Taq DNA Polymerase (Invitrogen Inc., Carlsbad, CA, USA), and $3.8 \mu \mathrm{L}$ sterile water to complete the total volume. PCR was carried out in 2 steps: the first step consisted of denaturation $\left(68^{\circ} \mathrm{C}\right.$ for $2 \mathrm{~min}, 95^{\circ} \mathrm{C}$ for $\left.30 \mathrm{~s}\right)$ followed by 30 cycles of $35 \mathrm{~s}$ at $92^{\circ} \mathrm{C}, 35 \mathrm{~s}$ at the primer-specific annealing temperature (Table 1), and $35 \mathrm{~s}$ at $72^{\circ} \mathrm{C}$. The second step consisted of 15 cycles of $30 \mathrm{~s}$ at $92^{\circ} \mathrm{C}, 35 \mathrm{~s}$ at $53^{\circ} \mathrm{C}, 35 \mathrm{~s}$ at $72^{\circ} \mathrm{C}$, which were followed by a final extension at $72^{\circ} \mathrm{C}$ for $30 \mathrm{~min}$. PCR products were visualized on an automated ABI $3130 \mathrm{xl}$ Genetic Analyzer (Applied Biosystems, Thermo Fisher Scientific, Waltham, MA, USA), and allele sizes were scored using GeneScan 500 ROX dye (Applied Biosystems) and analyzed with the GeneMapper software (version 4.0; Applied Biosystems).

After genotyping, the dataset was checked with the Micro-Checker program (version 2.2.3) (Van Oosterhout et al., 2004) to detect potential errors that might have occurred at each locus during the genotyping, such as null alleles, stuttering, and large allele dropouts. Next, the genetic diversity measures were calculated. The heterozygosities (observed and expected) and the Hardy-Weinberg equilibrium (HWE) were estimated using the MSTOOLS (version 3) (Park, 2001) and GENEPOP (Rousset, 2008) programs, respectively. The descriptive sta- 
New microsatellite markers for Anopheles nuneztovari s.l.

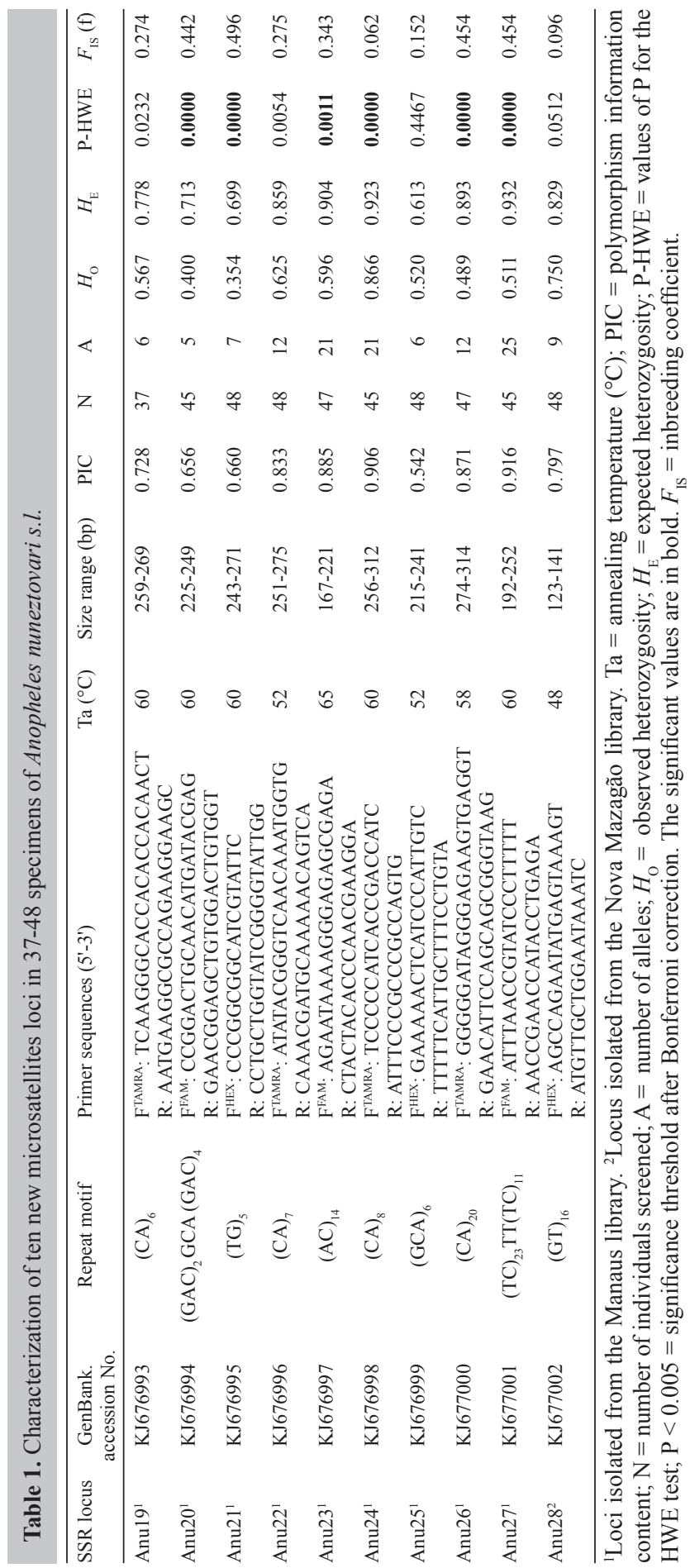


tistics, number of alleles per locus, linkage disequilibrium (LD), inbreeding coefficient $\left(F_{\mathrm{IS}}\right)$, and allele size range were inferred using the FSTAT program (version 2.9.3) (Goudet, 2002).

\section{RESULTS AND DISCUSSION}

Of the 10 microsatellite loci characterized in this study, 2 were trinucleotides and 8 were dinucleotides (Table 1), and all were highly polymorphic. The number of alleles per locus ranged from 5 (locus Anu20) to 25 (locus Anu27) (Table 1), with a mean of 12.4. The observed heterozygosity $\left(H_{\mathrm{O}}\right)$ ranged from 0.354 (locus Anu21) to 0.866 (locus Anu24), whereas the expected heterozygosity $\left(H_{\mathrm{E}}\right)$ ranged from 0.613 (locus Anu25) to 0.932 (locus Anu27).

After Bonferroni correction, 6 of the 10 loci showed significant deviation from the HWE, suggesting a heterozygote deficit; consequently, the $F_{\text {IS }}$ values were positive, ranging from 0.062 (locus Anu24) to 0.496 (locus Anu21), which indicated inbreeding. No significant LD was detected among the loci after Bonferroni correction. The significant deviation from the HWE suggests the presence of null alleles in most of the loci and may reflect accumulation of different mutations in primer-flanking regions, which would prevent PCR amplification of one or more alleles and result in significant heterozygote deficits. In the case of locus Anu24 with its 21 alleles, deviation from HWE $(\mathrm{P}<0.0001)$ may have occurred due to the very low expected values for genotypic classes, which would have increased the chi-square values, thus causing disequilibrium. This hypothesis is supported by the low $F_{\text {IS }}$ values $(0.062)$ for locus Anu24. However, for the other loci in disequilibrium we cannot completely rule out the possibility that such deviations may be a result of population subdivision (the Wahlund effect) in the sample from Manaus. This hypothesis arose from analyses of the COI gene (Scarpassa and Conn, 2011), which revealed 2 sympatric well-supported clades in samples from Manaus, suggesting 2 sympatric genetic lineages or species.

The novel A. nuneztovari s.l. microsatellite loci set described in this study is a marker set that will be highly useful in investigations of the population structure and evolutionary genetics of this neotropical malaria vector, and thus, will support the production of information that is of vital importance for malaria control efforts in areas where A. nuneztovari s.l. occur.

\section{ACKNOWLEDGMENTS}

We thank Dr. Vera Maria Fonseca de Almeida e Val (LEEM, INPA, Manaus) for kindly providing the clone sequencing data. We also thank MSc. Marcos Prado and MSc. Tatiana Cardoza for help in sequencing of the clones. A.S. Cunha-Machado has a scholarship (DCTA-C) from FAPEAM-Universal Amazonas. Research supported by INPA/MCTI; FAPEAM-Universal Amazonas [process \#3111/2012] and PRO-EQUIPAMENTO-CAPES.

\section{REFERENCES}

Cardoza TB, Sousa ACB, Lima MP, Souza AP, et al. (2011). Microsatellite markers for the neotropical malaria vector Anopheles nuneztovari sensu lato: isolation, development and characterization of eighteen loci. Mol. Ecol. Resour. 11: 1-3. Available at [http://tomato.bio.trinity.edu/manuscripts/11-4/mer-11-0032.pdf].

de Arruda M, Carvalho MB, Nussenzweig RS, Maracic M, et al. (1986). Potential vectors of malaria and their different susceptibility to Plasmodium falciparum and Plasmodium vivax in northern Brazil identified by immunoassay. Am. J. Trop Med. Hyg. 35: 873-881.

Foster PG, Bergo ES, Bourke BP, Oliveira TM, et al. (2013). Phylogenetic analysis and DNA-based species confirmation 
in Anopheles (Nyssorhynchus). PLoS One 8: e54063.

Gabaldón A (1981). Anopheles nuneztovari: important vector y agente de malaria refractaria en Venezuela. Bol. Dir. Malariol. Saneam. Amb. XXI: 28-38.

Galardo AK, Arruda M, D'Almeida Couto AA, Wirtz R, et al. (2007). Malaria vector incrimination in three rural riverine villages in the Brazilian Amazon. Am. J. Trop. Med. Hyg. 76: 461-469.

Goudet J (2002). FSTAT Version 2.9.3: A Program to Estimate and Test Gene Diversities and Fixation Indices. Available at [http://www2.unil.ch/popgen/softwares/fstat.htm]. Accessed November 1, 2013.

Lounibos LP, Wilkerson RC, Conn JE, Hribar LJ, et al. (1998). Morphological, molecular, and chromosomal discrimination of cryptic Anopheles (Nyssorhynchus) (Diptera: Culicidae) from South America. J. Med. Entomol. 35: 830-838.

Mirabello L and Conn JE (2008). Population analysis using the nuclear white gene detects Pliocene/Pleistocene lineage divergence within Anopheles nuneztovari in South America. Med. Vet. Entomol. 22: 109-119.

Park SDE (2001). Trypanotolerance in West African Cattle and the Population Genetic Effects of Selection. Ph.D. thesis, University of Dublin, Dublin.

Póvoa MM, Wirtz RA, Lacerda RNL, Miles MA, et al. (2001). Malaria vectors in the municipality of Serra do Navio, State of Amapá, Amazon Region, Brazil. Mem. Inst. Oswaldo Cruz 96: 179-184.

Risterucci AM, Duval MF, Rohde W and Billote N (2005). Isolation and characterization of microsatellite loci from Psidium guajava L. Mol. Ecol. Notes 5: 745-748.

Rousset F (2008). Genepop'007: a complete re-implementation of the Genepop software for Windows and Linux. Mol. Ecol. Resour. 8: 103-106.

Sambrook J and Russell DW (2001). A Laboratory Manual. Cold Spring Harbor Laboratory Press, New York.

Scarpassa VM and Conn JE (2011). Mitochondrial DNA detects a complex evolutionary history with Pleistocene Epoch divergence for the neotropical malaria vector Anopheles nuneztovari sensu lato. Am. J. Trop. Med. Hyg. 85: 857-867.

Scarpassa VM, Tadei WP and Suarez MF (1996). Allozyme differentiation among allopatric populations of Anopheles nuneztovari (Diptera: Culicidae). Braz. J. Genet. 19: 265-269.

Scarpassa VM, Tadei WP and Suarez MF (1999). Population structure and genetic divergence in Anopheles nuneztovari (Diptera: Culicidae) from Brazil and Colombia. Am. J. Trop. Med. Hyg. 60: 1010-1018.

Schuelke M (2000). An economic method for the fluorescent labeling of PCR fragments. Nat. Biotechnol. 18: 233-234.

Tadei WP, Thatcher BD, Santos JM, Scarpassa VM, et al. (1998). Ecologic observations on anopheline vectors of malaria in the Brazilian Amazon. Am. J. Trop. Med. Hyg. 59: 325-335.

Temnykh S, DeClerck G, Lukashova A, Lipovich L, et al. (2001). Computational and experimental analysis of microsatellites in rice (Oryza sativa L.): frequency, length variation, transposon associations, and genetic marker potential. Genome Res. 11: 1441-1452.

Trindade DB and Scarpassa VM (2002). Genetic differentiation and diagnostic loci among Anopheles (Nyssorhynchus) rangeli, An. (Nys.) nuneztovari, and An. (Nys.) dunhami (Diptera: Culicidae) in the Brazilian Amazon. J. Med. Entomol. 39: 613-620.

Van Oosterhout C, Hutchinson WF, Wills DPM and Shipley P (2004). MICRO-CHECKER: software for identifying and correction genotyping errors in microsatellite data. Mol. Ecol. Notes 4: 535-538. 